\title{
Root canal obturation: experimental study on the thermafil system related to different irrigation protocols
}

\author{
Guido Migliau, DDS 1 \\ Afrah Ali Abdullah Sofan, PhD1 \\ Eshrak Ali Abdullah Sofan, PhD1 \\ Salvatore Cosma, MD2 \\ Stefano Eramo, DDS² \\ Livio Gallottini, DDS ${ }^{1}$ \\ 1 Department of Oral and Maxillo-Facial Sciences,
"Sapienza" University of Rome, Italy
2 University of Perugia, Italy
}

Corresponding author:

Afrah Ali Abdullah Sofan

Department of Dental and Maxillo-Facial Sciences, "Sapienza" University of Rome

Viale Regina Elena 287/a

00198 Rome, Italy

E-mail: afrahy28@yahoo.it

\section{Summary}

Aim. The aim of this study was to stress the ability of a specific obturation technique (thermafil technique) to seal root canal system in presence or absence of smear layer.

Methodology. Sixteen monoradicular teeth, extracted for periodontal reasons, were collected for this study. All specimens were prepared with nickel-titanium rotary files, and then divided into two groups: for each group was applied a different kind of irrigation method, verifying the effectiveness in removing the smear layer, thus rendering the dentinal tubules more permeable for penetration of softened gutta-percha. Thermafil system was used to fill the root canals, and then all the specimens were observed under scanning electron microscope (SEM).

Results. The results showed that the Group which followed irrigation only with sodium hypochlorite exhibited significantly less gutta-percha tags when compared to the second Group, which was irrigated with sodium hypochlorite and EDTA.

Conclusion. The thermafil systems have a very good quality of compression and fluency that permit to gain a good seal of endodontic space; furthermore it allows the penetration of gutta-percha with the formation of numerous of gutta-percha tags inside the dentinal tubules above all when smear layer is reduced or eliminated.
Key words: smear layer, sodium hypochlorite, EDTA (Ethylene diaminetetraacetic acid), thermafil, gutta-percha tags, dentinal tubules.

\section{Introduction}

Long-term seal of root canal system plays an important role in supporting the healing of periapical tissues and prevents intracanal recontamination after root canal treatment (1). Since a complete apical and coronal seal of the canal system are prerequisites for a successful nonsurgical root canal treatment, the comparison and evaluation of current obturation techniques are very important to determine the probability of their efficacy in achieving this optimal goal (2). Many studies have shown that microleakage adversely affects the success of root canal therapy $(3,4)$. Thus, the passage of microorganisms and their toxins in the periradicular tissues can induce inflammation in the periradicular tissues $(5,6)$ and consequently reduce the success rate of the root canal therapy. A three dimensional apical seal, however, that addresses these ramifications will prevent leakage and the potential for reinfection of the root canal and of the periradicular tissues. With the advent of the thermoplasticized gutta-perch technique, new obturation techniques have been introduced to achieve a three dimensional obturation of the canal system. In 1978, WB Johnson (7) described a technique for the obturation of root canals with thermoplasticised gutta-percha. A few years later, the thermafil device was introduced by Tulsa Dental. The "Thermafil" is a patented endodontic obturator consisting of flexible central carrier made of stainless steel, titanium, or plastic uniformly coated with a layer of $\alpha$-phase gutta-percha (8). When heated the gutta-percha becomes thermoplasticized and adheres to the carrier. When inserted into the prepared canal, carrier transports gutta-percha in the root canal and remains in the canal as part of obturation (9). Further development of the original technique led to the production of Thermafil Plus endodontic Obturators (Tulsa Dental Products, Tulsa, OK, USA) that presently use plastic carriers for the delivery of softened gutta-percha (2). Thermoplasticized gutta-percha techniques have been demonstrated to provide superior adaptation to canal walls and filling of lateral canals compared with lateral compaction $(10,11)$. During the use of all thermoplasticized gutta-percha techniques, the softened gutta-percha can easily be moved into the canal irregularities. Recently, the manufacturer of Thermafil (DENTSPLY Tulsa Dental Specialties, Tulsa, OK) has 
developed a carrier-based obturation that uses a proprietary crosslinked gutta-percha core instead of using plastic carriers. According to the manufacturer, GuttaCore can be removed with greater ease than other carrier-based systems; however, it is important to note that the core behaves unlike gutta-percha in that it does not readily dissolve with solvents and it is not as amenable to plasticizing with heat (12). Many authors have proposed that the smear layer that is present following canal cleaning and shaping prevents the penetration and adaptation of the softened root canal filling material into the dentinal tubules (13, 14). Studies have shown that smear layer can serve as an avenue for leakage of microorganisms and as a source for growth and activity of viable bacteria which remain entrapped in dentinal tubules (15-17). In the presence of the smear layer, apical leakage can be increased in canals obturated with gutta-percha (17). By removing this layer, surface contact between the canal wall and the filling material can be increased, and thus apical seal may be improved $(14,18)$, thereby decreasing the occurrence of bacterial leakage $(13,16,19-21)$. The most effective chemical method for removing the smear layer has been shown to be irrigated with $10 \mathrm{~mL} 17 \%$ EDTA followed by $10 \mathrm{~mL}$ $5.25 \% \mathrm{NaOCl}$ prior to obturation $(14,22,23)$. The purpose of this study was to evaluate the efficacy of sodium hypochlorite associated with EDTA to remove the smear layer and to determine the percentage of gutta-percha tags in the apical, middle and coronal thirds of root canals when filled with thermoplasticized gutta-percha techniques (Thermafil System) using scanning electron microscope (SEM).

\section{The importance of irrigation in endodontic system}

The aim of irrigation in root canal treatment is to improve the cleaning and disinfection process within the root canal system. Irrigation serves as a physical flush to remove debris as well as serves as antimicrobial agent, tissue solvent and lubricant. Root canal irrigation plays a key role in the success of endodontic treatment, because it helps in the progressive removal of the smear layer and neutralizes the root canal microbial flora.

The smear layer is a combination of organic and inorganic debris that is present on the root canal walls following instrumentation; it's composed of dentinal shavings, tissue debris, odontoblastic processes, and microbial elements (24). The first researchers to describe the smear layer on the surface of instrumented root canals were McComb and Smith in 1975 (25). Identification of the smear layer was made possible using the electron microprobe with scanning electron microscope (SEM) attachment, and first reported by Eick in 1970 (26). These workers showed that the smear layer was made of particles ranging in size from less than 0.5-15 $\mu \mathrm{m}$. Scanning electron microscope studies of cavity preparations by Brännström and Johnson in 1974 (27) demonstrated a thin layer of grinding debris. They estimated it to be $2-5 \mu \mathrm{m}$ thick, extending a few micrometres into the dentinal tubules. Mader in 1984 (28) reported that the smear layer thickness was generally 1-2 $\mu \mathrm{m}$.

Mader described the smear material in two parts: first, superficial smear layer (Fig. 1) and second, the material packed into the dentinal tubules. Packing of smear debris was present in the tubules to a depth of $40 \mu \mathrm{m}(24)$.

The presence of the smear layer has been postulated to be an avenue for leakage and source of substrate for bacterial growth and ingress $(15,23,29,30)$. Studies have shown that smear layer on the dentinal walls of biomechanically instrumented root canals occluded the dentinal tubules. Technically, the smear layer may interfere with the penetration of gutta-percha into the tubules and the adhesion and penetration of root canal sealers into the dentinal tubules (14, 19, 31, 32).

The most effective chemical method for removing the smear layer has been shown to be irrigated with 10 $\mathrm{mL} 5.25 \% \mathrm{NaOCl}$ followed by $10 \mathrm{~mL} 17 \%$ EDTA prior to obturation $(14,22,27)$. Many of the compounds used for irrigation have been chemically modified and several mechanical devices have been developed to improve the penetration and effectiveness of irrigation (33-35).

Some irrigating solutions dissolve either organic or inorganic tissue in the root canal. In addition, several irrigating solutions have antimicrobial activity and actively kill bacteria and yeasts when introduced in direct contact with the microorganisms. In endodontic the most commonly used irrigating solution is sodium hypochlorite $(\mathrm{NaOCl})$ (36-38). But sodium hypochlorite by itself is not sufficient for total cleaning of the endodontic system (9). It has no effect on the smear layer and its high surface tension does not allow for its cleaning and disinfection of the root canal system's totality. For this reason, and according to the different clinical situations, we will have to use other irrigants in combination with sodium hypochlorite. Another irrigant that could be used in combination with sodium hypochlorite, is EDTA (17\%) (Ethylene diaminetetraacetic acid) (Smear Clear) (SybronEndo, Orange, CA).

Sodium hypochlorite is the most widely used as an endodontic irrigant in contemporary endodontic prac-

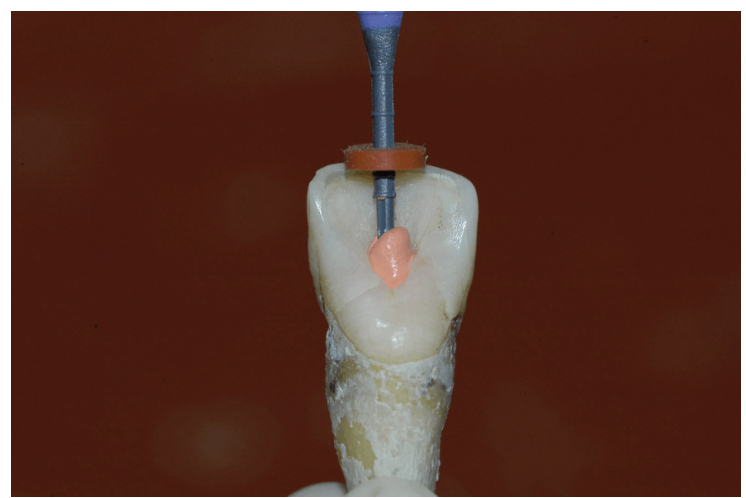

Figure 1. Thermafil obturation of the specimens. 
tice and is arguably still the preferred irrigating solution as it fulfills most of the criteria stipulated for an ideal irrigant. Sodium hypochlorite is non-specific and is capable of killing a wide spectrum of microorganisms, ranging from bacteria to fungi and viruses. It is considered the main root canal irrigant because of its broad-spectrum antimicrobial action and tissue dissolving properties against most microorganisms $(23$, 39 ). It is an excellent irrigant in terms of its ability to function as a lubricant during biomechanical preparation of the root canals, and to dissolve pulpal necrotic tissues and the organic components of the smear layer. It is highly alkaline $(\mathrm{pH} \mathrm{11-12.5)}$ and is a strong oxidizing agent of proteins. The mechanism through which sodium hypochlorite exerts its bactericidal effects is believed to be associated with the oxidative action of undissociated hypochlorous acid on the sulphydryl groups of bacterial enzymes. The inhibition of these enzymes results in interference with metabolic functions and ultimately death of the bacteria. Some microscopic studies have shown that complete dissolution of biofilms by sodium hypochlorite is possible using the direct contact test del Carpio-Perochena in 2011 (40), incomplete dissolution and residual biofilm appears to be common under clinical conditions following full-strength $\mathrm{NaOCl}$ irrigation. Residual biofilm may contain viable bacteria and may decrease the interfacial adaptation of root filling materials. Several models of biofilms are used in endodontic research, and the efficacy of $\mathrm{NaOCl}$ depends on variables such as the method of biofilm growth, $\mathrm{NaOCl}$ concentration and exposure time. It could also be considered that oral mixed biofilms can be more resistant and have a greater adhesion to dentine in comparison with biofilms developed under laboratory conditions.

Various concentrations of sodium Hypochlorite (NaO$\mathrm{Cl})$ have been used as root canal irrigants for many decades. Zhang in 2010 (41) evaluated the effect of initial irrigation with 2 different $\mathrm{NaOCl}$ concentrations (1.3 and $5.25 \%$ ) on the erosion of radicular dentin and concluded that $5.25 \% \mathrm{NaOCl}$ increased dentinal erosion compared with $1.3 \% \mathrm{NaOCl}$. The penetration of $\mathrm{NaOCL}$ into the dentin is limited. At high concentrations it is toxic, whereas at low concentrations it is ineffective against E. faecalis strains. The use of sodium hypochlorite is not without risk due to its cytotoxicity and ability to cause necrosis, haemolysis and skin ulceration. Swelling, extra-oral ecchymosis and ulceration of the oral soft tissues have been reported following extrusion of sodium hypochlorite. The effects of sodium hypochlorite on necrotic tissue are due to the hypertonicity of the solution. Although several chemical agents are available with different properties, as far as cleaning of root canals is concerned, no currently available endodontic irrigant fulfills all ideal physicochemical properties to covers all of the functions required from an irrigant, which act simultaneously on the organic and inorganic components of smear layer. Therefore, interesting is the combination of different irrigation protocols to provide better cleaning, antisepsis, and neutralization of toxic products present in the root canal system. A number of chemical agents and/or physical methods have been investigated to remove the debris and smear layer. Ethylene diaminetetraacetic acid (EDTA) is the most commonly used solution. The EDTA is an aminopolycarboxylic acid and a colourless, water soluble solid. It is widely used to dissolve lime scale. The compound was first described in 1935 by Ferdin and Munz, who prepared the compound from ethylenediamine and chloroactic acid. The combined action of $\mathrm{NaOCl}$ and EDTA, causing changes on collagen matrix and demineralization of root dentin with consequent exposure of collagen, respectively results in a decrease of dentin microhardness as observed in many experimental studies. This effect probably contributes to increase the incidence of fractures and/or cracks (42). The chelating action of EDTA solution induces an adverse softening potential on the calcified components of dentin and consequently a reduction in the microhardness was expected. Also, the dissolving action of $\mathrm{NaOCl}$ on the organic collagen components of dentin explains how the alternated irrigation with these solutions affects the hardness of dentin.

The combination of $\mathrm{NaOCl}$ and EDTA at a 1:1 ratio increases the effect of the chelating agent. The combination of these solutions increases the $\mathrm{pH}$, producing an alkaline environment in which EDTA has higher affinity for calcium ions. Saleh and Ettman in 1999 (43), reported similar results to those of the present study as they found that the use of $5 \% \mathrm{NaOCl}$ alternated with $17 \%$ EDTA reduced significantly root dentin microhardness. However, it has also been reported that the combination of $\mathrm{NaOCl}$ and EDTA can potentialize the erosion of the dentin walls when the smear layer is removed. Rajasingham in 2010 (44) verified that alternate irrigation with $5 \% \mathrm{NaOCl}$ and $17 \%$ EDTA resulted in increases of tooth surface strain. Those authors explain that the alternate irrigation with $5 \% \mathrm{NaOCl}$ and $17 \%$ EDTA probably allows the alternate depletion of organic and inorganic material, with a greater accumulative depth of effect on dentine and therefore tooth surface strain. They also emphasize that the increase in strain, although significant, does not yet indicate whether it is sufficient to result in increased risk of tooth fracture due to fatigue.

\section{Materials and methods}

Sixteen human single rooted teeth extracted for periodontal reasons, whereas the exclusion previous root canal treatment. They were collected and cleaned of extraneous tissue, calculus and then rinsed and stored in distilled water. Before instrumentation, the teeth were randomly divided into two groups of 8 teeth each, according to the method and types of irrigation. Group 1, the root canals were irrigated only with sodium hypochlorite at $5 \% \mathrm{NaOCl}$ (Niclor - Ogna Laboratori Farmaceutici). Each tooth received an equal gross amount of time (30') for irrigation and the same volume $(10 \mathrm{ml})$ of sodium 
hypochlorite using 30 gauge open-ended needle (NaviTip ultradent, UT). Group 2, the root canals were irrigated with sodium hypochlorite $5 \% \mathrm{NaOCl}$ alternated with 17\% EDTA (Ogna Laboratori Farmaceutici). Each tooth received an equal gross amount of time (30') for irrigation: $5 \mathrm{ml}$ of sodium hypochlorite and $5 \mathrm{ml}$ of EDTA using, for each irrigant, a 30 gauge open-ended needle (NaviTip ultradent, UT). After access opening using a round diamond bur mounted on a high-speed handpiece, the working length (WL) was determined by inserting a \#10 K-file (Dentsply Maillefer, Ballaigues, Switzerland) into the canal until it was just visible at the apical foramen, then subtracting $1 \mathrm{~mm}$. Apical patency was maintained throughout instrumentation using a \#15 K-file (Dentsply Maillefer). The canals were instrumented using a crown-down technique with rotary ProTaper nickel-titanium files (Dentsply Maillefer) to a master apical file size of $0.25 \mathrm{~mm}$. The instruments were used with X-smart Device (Dentsply Maillefer) with $16: 1$ reduction rotary handpiece X-smart-contra-angle (Dentsply Maillefer); the speed of rotation was maintained at $250 \mathrm{rpm}$ with torque $52 \mathrm{Ncm}$. ProTaper files were used according to the manufacture's recommendation. Briefly, the pulp chamber was filled with $5 \%$ sodium hypochlorite $(\mathrm{NaOCL})$ solution, and $\mathrm{S} 1$ file was taken into the canal just short of depth. Then the canal was irrigated, and the auxiliary SX file was used to remove the coronal aspect of the canal away from furcal danger and to improve radical access.

Shaping with the auxiliary SX was continued with brushing motion until two thirds of its cutting blades were below the orifice. The canal was irrigated, and a size $10 \mathrm{~K}$-file (Dentsply Maillefer) was used for recapitulation. Preparation continued with S1, S2, F1 and F2 files to working length. At the end of instrumentation (with F2 - size 25), the apical foramen gauging was performed by using NiTi K-files 0.2 taper, then, according to the size of the gauging, authors finished preparation with $\mathrm{NiTi}$ rotary instruments of larger diameter than 25 (F3,F4,F5). Basing on this final diameter obtained and on master apical file that were fitted to the working length, the correct thermafil obturator was selected. The teeth were irrigated after each change of instrument with only $5 \%$ sodium hypochlorite $(\mathrm{NaOCl})$ for Group 1 and alternation of $5 \%$ sodium hypochlorite $(\mathrm{NaOCl})$ with ethylene diaminetetraacetic acid (EDTA) at $17 \%$ for Group 2. All canals were dried with sterile paper points then they were filled with thermafil system (Maillefer) without using endodontic cement (Figs. 1, 2). All teeth were anchored in gauge blocks of resin, then they were immersed in hydrochloric acid at 15\% for twelve hours in order to obtain the dissolution of enamel and dentin and expose the gutta-percha that present in canals (Fig. 3). The evaluation of the presence of gutta-percha tags in all samples was performed using a scanning electron microscope (SEM), distinctly observing the coronal, middle and apical third of root canals.

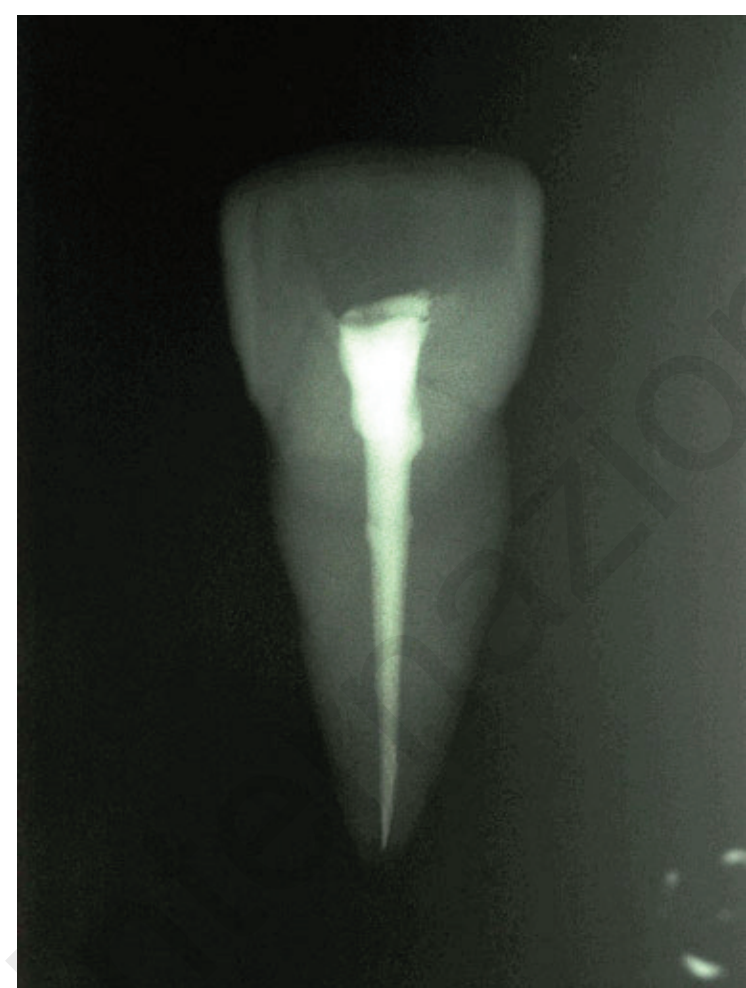

Figure 2. X-ray of a specimen.

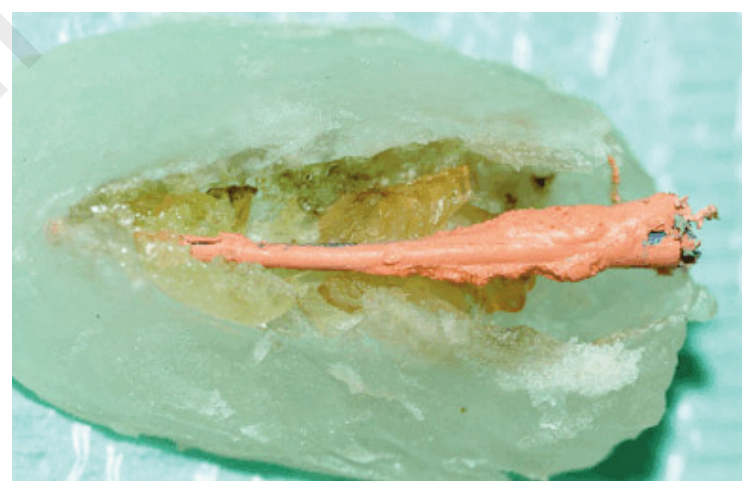

Figure 3. The teeth were immersed in hydrochloric acid $15 \%$ to obtain the dissolution of inorganic part.

\section{Statistical analysis}

All specimens were observed in a series of 48 photos with SEM (three photos for each specimen in the apical, middle, and coronal third). The photos were used to determine the statistical analysis by applying the Kruskall-Wallis test (is the one-way analysis of variance Anova); the analysis shows significant differences $(P<0.05)$ between the number of gutta-percha tags within the obturation techniques as a function of defect location (apical, middle, and coronal third) on base of the two types of irrigation.

The presence or absence of gutta-percha tags were evaluated in the assessment criteria reported in Table 1. 
Table 1. Scale that represents the percentage of gutta-percha surface with the presence of gutta-percha tags.

\begin{tabular}{ll}
\hline Number & Gutta-percha tags on the surface \\
\hline 0 & No reproduction of tags \\
1 & Gutta-percha tags $<25 \%$ \\
2 & $25 \%<$ Gutta-percha tags $<50 \%$ \\
3 & $50 \%<$ Gutta-percha tags $<57 \%$ \\
4 & Gutta-percha tags $>75 \%$ \\
\hline
\end{tabular}

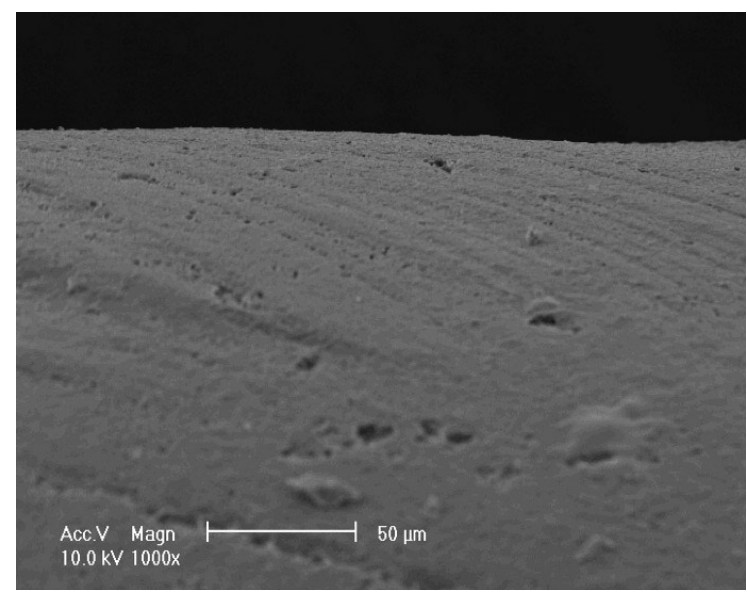

Figure 4. (SEM, $1000 \mathrm{x}$ ) Gutta-percha in the coronal third of canal (only $\mathrm{Naocl}$ ).

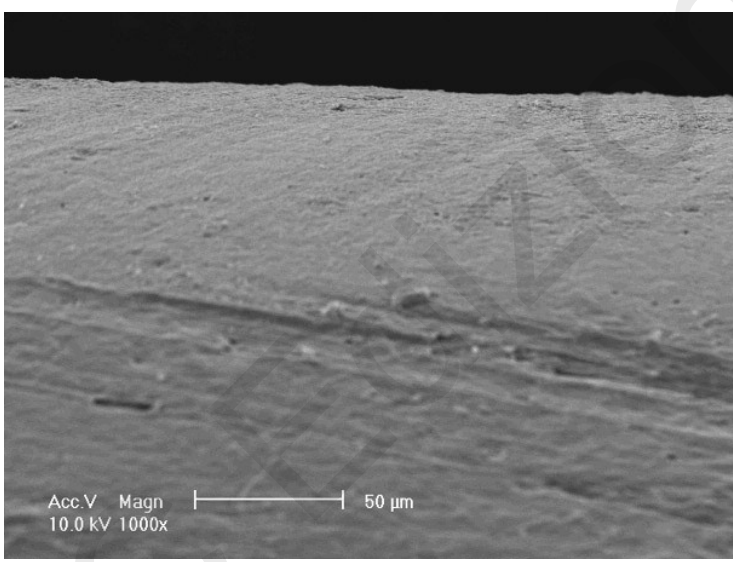

Figure 5. (SEM, $1000 \mathrm{x}$ ) Gutta-percha in middle third of canal (only Naocl).

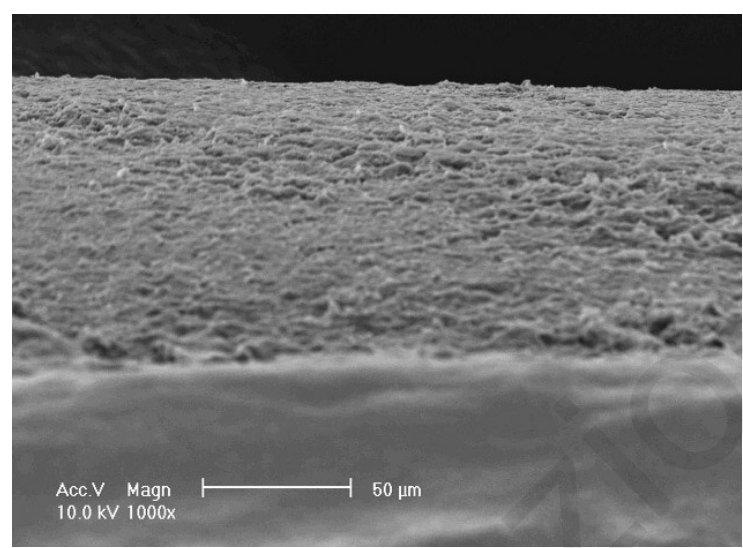

Figure 6. (SEM, $1000 \mathrm{x})$ Gutta-percha in apical third of canal (only Naocl).

\section{Results and discussion}

The evaluation of the presence of gutta-percha tags in all samples was performed using a scanning electron microscope (SEM), distinctly observing the coronal, middle and apical third of root canals.

The results showed that Group 1 (Figs. 4-6) followed with irrigation only with sodium hypochlorite exhibited significantly $(P<0.05)$ less gutta-percha tags when compared to Group 2, which was irrigated with sodium hypochlorite in combination with EDTA.

The obtained results were submitted for statistical analysis of GP tags were summarized in the Table 2.

Final irrigation with 17\% EDTA for 2 min has been recommended for removal of smear layer from root canal walls, especially at the cervical and middle thirds. Therefore, it can be noticed from the internal analysis that excellent of gutta-percha penetration fundamentally from the coronal and the middle area of the root canal instead of the apical portion (Figs. 7, 8). The structure of apical dentin presents a decreased number of dentin tubules and the filling techniques used may affect the adaptation and the penetration of the materials (Fig. 9). Shemesh in 2006 (45) postulated that, because the dentinal tubule configuration is less dense in the apical portion than in the coronal portion of the root, this might compromise bonding in the apical region. As well, it is known that bonding is further compromised in sclerotic dentin, which is more common in the apical portions of adult teeth (46).

Table 2. Number of specimens for the coronal, medium and apical third with different percentage of gutta-percha tags on the surface (indicated as a numeric value in the scale reported in Table 1) in the two kind of irrigation protocol Groups.

\begin{tabular}{|c|c|c|c|c|c|}
\hline $\begin{array}{l}\text { Irrigation } \\
\text { protocols }\end{array}$ & & Third coronal & Third medium & Third apical & All \\
\hline \multirow[t]{2}{*}{$\begin{array}{l}\text { Group } 1 \\
\text { Hypochlorite }\end{array}$} & $\begin{array}{l}\text { Percentage gutta-percha tags } \\
\text { (scale in Table 1) }\end{array}$ & 1234 & 1234 & 1234 & 1234 \\
\hline & N. of specimens & 7100 & 8000 & 8000 & 23100 \\
\hline $\begin{array}{l}\text { Group } 2 \\
\text { Hypochlorite }\end{array}$ & $\begin{array}{l}\text { Percentage gutta-percha tags } \\
\text { (scale in Table 1) }\end{array}$ & 1234 & 1234 & 1234 & 1234 \\
\hline +EDTA & N. of specimens & 0134 & 0143 & 1511 & 1788 \\
\hline
\end{tabular}




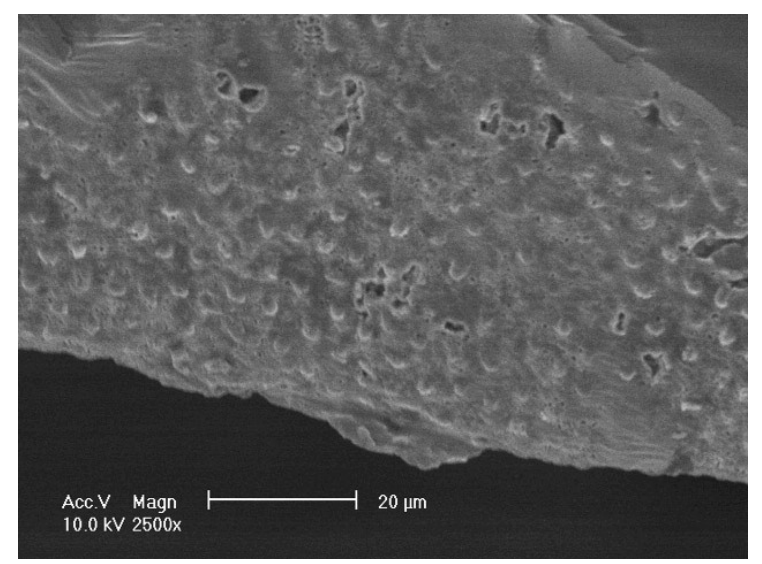

Figure 7. (SEM, $1000 \mathrm{x}$ ) Gutta-percha in the coronal third of canal (Naocl+EDTA).

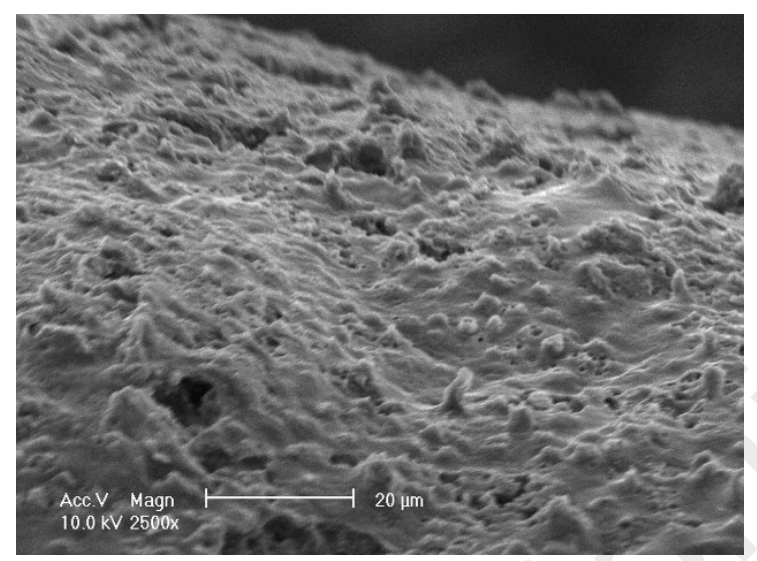

Figure 8. (SEM, $1000 \mathrm{x}$ ) Gutta-percha in the middle third of canal (Naocl+EDTA).

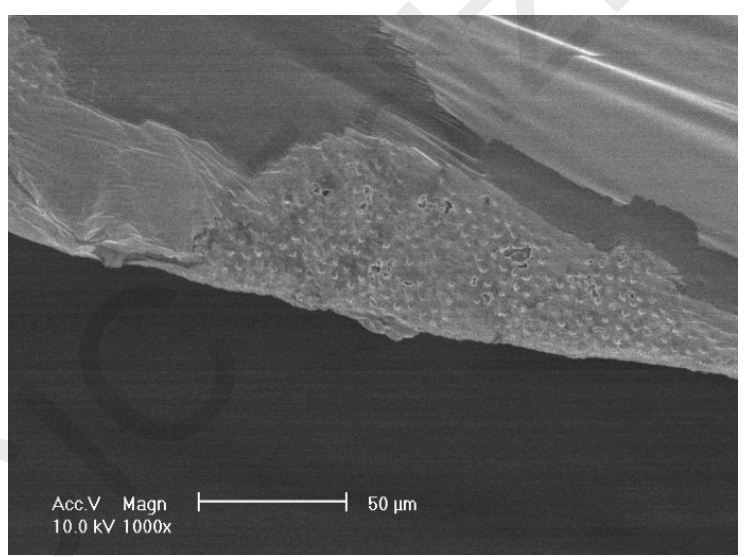

Figure 9. (SEM, $5000 \mathrm{x}$ ) Gutta-percha in the apical third of canal (Naocl +EDTA).

\section{Conclusions}

According to the date of the present study it seems possible to reach the following conclusions:

1. The evaluation method that we have proposed for the measurement of the number of gutta-percha
Tags in the dentinal tubules is complete and easy to apply.

2. It is evident the superiority of the irrigation with hypochlorite +EDTA compared to the single irrigation with hypochlorite to obtain the penetration of gutta-percha in the dentinal tubules.

3. The penetration of gutta-percha can be an indirect indicator of the ability of irrigants in the removal of endodontic smear layer.

4. The thermafil system possesses a very good quality of compression and fluency that allows the penetration of gutta-percha with the formation of numerous of gutta-percha tags inside the dentinal tubules and good seal of the endodontic space.

\section{References}

1. Stoll R, Betke K, Stachniss V. The influence of different factors on the survival of root canal fillings: a 10-year retrospective study. J Endod. 2005;31:783-90.

2. Kytridou V, Gutmann JL, Nunn MH. Adaptation and seal ability of two contemporary obturation techniques in the absence of the dentinal smear layer. Int Endo J. 1999;32:464-474.

3. Naidorf IJ. Clinical microbiology in endodontics. Dent Clin North Am.1974;18:329-44.

4. Saunders WP, Saunders EM. Influence of smear layer and the coronal leakage of thermafil and laterally condensed gutta percha root fillings with a glass ionomer sealer. J Endod. 1994;20:155-8.

5. Yoshida M, Fukushima H, Yamamoto K, Ogawa K, Toda T, Sagawa H. Correlation between clinical symptoms and microorganisms isolated from root canals of teeth with periapical pathosis. J Endod. 1987;13:24-8.

6. Nair PNR, Sjogren U, Krey G, Kahnberg KE, Sundiqvist G. Intraradicular bacteria and fungi in root-filled asymptomatic human teeth with therapy-resistant periapical lesions: a longterm light and electron microscopic follow-up study. J Endod. 1990;12:580-8.

7. Johnson WB. A new gutta-percha technique. J Endod.1978;4:184-8.

8. Lares C, elDeeb ME. The sealing ability of the Thermafil obturation technique. J Endod.1990;16:474-9.

9. Bhambhani SM, Sprechman K. Microleakage comparison of thermafil versus vertical condensation using two different sealers. Oral Surg Oral Med Oral Pathol.1994;78:105-8.

10. Weller RN, Kimborough WF, Anderson RW. A comparison of thermoplastic obturation techniques: adaptation to the canal walls. J Endod. 1997;23:703-6.

11. Bowman CJ, Baumgartner JC. Gutta-percha obturation of lateral grooves and depressions. J Endod . 2002;28:220-3.

12. Beasley RT, Williamson AE, Justman BC. Time required to remove guttacore, thermfil plus, and thermoplasticized gutta-percha from moderately curved root canals with protaper files. J Endod. 2013;39:125-8.

13. Gutmann JL. Adaptation of injected thermoplasticized gutta-percha in the absence of smear layer. Int Endod J.1993;26:87-92.

14. Oksan $\mathrm{T}$, Aktener $\mathrm{BO}$, Sen $\mathrm{BH}$, Tezel $\mathrm{H}$. The penetration of root canal sealers into dentinal tubules. A scanning electron microscopic study. Int Endod J. 1993;26:301-5.

15. Pashley DH. Smear layer: physiological considerations. Oper Dent Suppl. 1984;3:13-29.

16. White RR, Goldman M, Sun Lin PS. Influence of the smear layer upon dentinal tubule penetration by plastic filling materials. J Endod. 1984;10:558-62. 
17. Kennedy WA, Walker WA 3rd, Gough RW. Smear layer removal effects on apical leakage. J Endod.1986;12:21-7.

18. Cergneux M, Ciucchi B, Dietschi JM, Holz J. The influence of the smear layer on the sealing ability of canal obturation. Int Endod J. 1987;20:228-32.

19. White RR, Goldman M, Sun Lin P. The influence of the smear layer upon dentinal tubule penetration by plastic filling materials. Part 2. J Endod. 1987;13:369-374.

20. Saunders WP, Saunders EM. The effect of smear layer upon the coronal leakage of gutta percha root filling and a glass ionomer sealer. Int Endod J. 1992;25:245-9.

21. Behrend GD, Cutler CW, Gutmann JL. An in vitro study of smear layer removal and microbial leakage along rootcanal fillings. Int Endod J. 1996; 29:99-107.

22. Goldman LB. The influence of several irrigating solutions for endodontics; A scanning electron microscopic study. Oral Surg Oral Med Oral Pathol. 1981;52:197-204.

23. Baumgartner JC, Mader CL. A scanning electron microscopic evaluation of four root canal irrigation regimens. J Endod. 1987;13:147-57.

24. Violich DR, Chandler NP. The smear layer in endodontics - a review. Int Endod J. 2010; 43:2-15.

25. McComb D, Smith DC. A preliminary scanning electron microscopic study of root canals after endodontic procedures. J Endod.1975;1:238-42.

26. Eick JD, Wilko RA, Anderson $\mathrm{CH}$, Sorensen SE. Scanning electron microscopy of cut tooth surfaces and identification of debris by use of the electron microprobe. J Dent Res. 1970;49:1359-68.

27. Brännström M, Johnson $\mathrm{G}$. Effects of various conditioners and cleaning agents on prepared dentin surfaces: a scanning electron microscopic investigation. J Prosthet Dent. 1974;31:422-30.

28. Mader CL, Baumgartner JC, Peters DD. Scanning electron microscopic investigation of the smeared layer on root canal walls. J Endod.1984; 10:477-83.

29. Goldman M, Goldman LB, Cavaleri R, Bogis J, Lin PS .The efficacy of several endodontic irrigating solutions: a scanning electron microscopic study: Part 2. J Endod.1982;8:487-92.

30. Pitt Ford TR, Roberts GI .Tissue response to glass ionomer retrograde root fillings. Int Endod J. 1990;23:233-8.

31. White RR, Goldman M, Sun Lin P. The influence of the smear layer upon dentinal tubule penetration by plastic filling materials. J Endod. 1984; 10:558-562.

32. Gettlemen BH, Messer HH, EIDeeb ME. Adhesion of sealer cements to dentine with and without the smear layer. J Endod. 1991;17:15-20.
33. Philippe S, Fadl K. Sequence of Irrigation in Endodontics. Oral Health. 2005;62-65.

34. Heling I, Chandler NP. Antimicrobial effect of irrigant combinations within dentinal tubules. Int Endod J.1998;31:8-14.

35. Vahdaty A, Pitt Ford TR, Wilson RF. Efficacy of chlorhexidine in disinfecting dentinal tubules in vitro. Endod Dent Traumatol. 1993;9:243-8.

36. Buck RA, Eleazer PD, Staat RH, et al. Effectiveness of three endodontic irrigants at various tubular depths in human dentin. J Endod. 2001;27:206-8.

37. Jean Sonne MJ, White RR. A comparison of $2.0 \%$ chlorhexidine gluconate and $5.25 \%$ sodium hypochlorite as antimicrobial endodontic irrigants. J Endod. 1994;20:276-8.

38. Zamany A, Safavi K, Spangberg LS. The effect of chlorhexidine as an endodontic disinfectant. Oral Surg Oral Med Ora Pathol Oral Radiol Endod. 2003;96:578-81.

39. Yamada RS, Armas A, Goldman M, Lin PS. A scanning electron microscopic comparison of a high volume final flush with several irrigating solutions: part 3. J Endod.1983; 9:13742.

40. Del Carpio-Perochena AE, Bramante CM, Duarte MA et al Biofilm dissolution and cleaning ability of different irrigant solutions on intraorally infected dentin. J Endod. 2011; 37:1134-8.

41. Zhang K, Tay FR, Kim YK, Mitchell JK, Kim JR, Carrilhof MI The effect of initial irrigation with two different sodium hypochlorite concentrations on the erosion of instrumented radicular dentin. Dent Mater. 2010;26:514-23.

42. Torabinejad M, Handysiders R, Khademi AA, Bakland LK Clinical implications of the smear layer in endodontics: A review. Oral Surg Oral Med Oral Pathol Oral Radiol Endod. 2002;94:658-66.

43. Saleh AA, Ettman WM. Effect of endodontic irrigation solutions on microhardness of root canal dentine. J Dent. 1999;27:43-6.

44. Rajasingham R, Ng YL, Knowles JC, Gulabivala K. The effect of sodium hypochlorite and ethylene diamine tetraacetic acid irrigation, individually and in alternation, on tooth surface strain. Int Endod J. 2010;43:31-40.

45. Shemesh $\mathrm{H}$, Wu MK, Wesselink PR. Leakage along apical root fillings with and without smear layer using two different leakage models: a two-month longitudinal ex vivo study. Int Endod J. 2006;39:968-76.

46. Paquè $F$, Luder HU, Sener B, Zehnder M. Tubular sclerosis rather than the smear layer impedes dye penetration into the dentine of endodontically instrumented root canals. Int Endod J. 2006;39:18-25. 